\title{
O entrelaçamento do movimento corporal expressivo da pessoa com deficiência no
}

\section{ambiente escolar}

The interlacement of expressive body movement of people with disabilities in school environment

La vinculación del movimiento corporal expresivo de las personas con discapacidad en el entorno

escolar

Recebido: 26/06/2021 | Revisado: 04/07/2021 | Aceito: 06/07/2021 | Publicado: 16/07/2021

\author{
Adrielle Andrade Passos \\ ORCID: https://orcid.org/0000-0002-9372-7430 \\ Universidade Federal de Sergipe, Brasil \\ E-mail: adrielle_passos@hotmail.com \\ Lavinia Teixeira-Machado \\ ORCID: https://orcid.org/0000-0002-0653-5853 \\ Universidade Federal de Sergipe, Brasil \\ E-mail: laviniateixeira@academico.ufs.br
}

\begin{abstract}
Resumo
As conceituações sobre a pessoa com deficiência (PCD) são discutidas no cenário político para refletir acerca das contribuições da educação de práticas corporais que envolvem a noção de corpo e as relações sociais intricadas, trazendo a dança como disparador essencial de possibilidades para a percepção, conscientização e uso do corpo, e consequentemente as inter-relações e inter-influenciações do indivíduo, com o propósito de dialogar a respeito dos direitos da PCD nos espaços educacionais. Destacam-se, na sistematização discursiva, os eixos da legislação vigente no país, da corporeidade, neurociência e da prática da dança, trazendo à luz a importância do ator coletivo mediante experiências vislumbradas num programa de dança específico para esta população, o qual utiliza princípios norteadores que encaminharam o processo baseando-se nas concepções propostas por Dalcroze, Feldenkrais, Laban e Pilates e leva em consideração três componentes fundamentais para a educação corporal através da dança: o eu, o ambiente, e o outro. O intuito é fomentar meios substanciais para a integração emocional, cognitiva, física e social no ambiente escolar.
\end{abstract}

Palavras-chave: Pessoas com deficiência; Neurociências; Dança; Ajustamento social; Instituições acadêmicas.

\begin{abstract}
The conceptions about people with disabilities (PWD) are discussed in the political scenario to reflect on the contributions of the education of corporal practices that involve the notion of body and the intricate social relations, bringing dance as an essential trigger of possibilities for the perception, awareness and use of the body, and consequently the interrelationships and inter-influences of the individual, with the purpose of dialoguing about the rights of the PWD in educational spaces. In the discursive systematization, the axes of current legislation in the country, corporeity, neuroscience and dance practice are highlighted, bringing to light the importance of the collective actor through experiences envisioned in a specific dance program for this population, which uses principles guiding the process based on the concepts proposed by Dalcroze, Feldenkrais, Laban and Pilates and taking into account three fundamental components for body education through dance: the self, the environment, and the other. The aim is to promote substantial means for emotional, cognitive, physical and social integration in the school environment.
\end{abstract}

Keywords: Disabled persons; Neurosciences; Dancing; Social adjustment; Schools.

\section{Resumen}

Las concepciones sobre las personas con discapacidad (PCD) se discuten en el escenario político para reflexionar sobre los aportes de la educación a las prácticas corporales que involucran la noción de cuerpo y las intrincadas relaciones sociales, trayendo la danza como un disparador esencial de posibilidades de percepción, conciencia y uso del cuerpo, y consecuentemente las interrelaciones e inter-influencias del individuo, con el propósito de dialogar sobre los derechos de la PCD en los espacios educativos. En la sistematización discursiva se destacan los ejes de la legislación vigente en el país, la corporeidad, la neurociencia y la práctica de la danza, sacando a la luz la importancia del actor colectivo a través de experiencias vislumbradas en un programa de danza específico para esta población, que utiliza principios rectores del proceso basado en los conceptos propuestos por Dalcroze, Feldenkrais, Laban y Pilates y teniendo en cuenta tres componentes fundamentales para la educación corporal a través de la danza: el yo, el entorno y el otro. El objetivo es promover medios sustanciales para la integración emocional, cognitiva, física y social en el entorno escolar.

Palabras clave: Personas con discapacidad; Neurociencias; Baile; Ajuste social; Instituciones académicas. 


\section{Introdução}

A deficiência é um conceito que se modifica ao longo do tempo e surge da interação entre condições de saúde e fatores contextuais. Pode se manifestar em graus variados e em ambos sexos, sem distinção de faixa etária ou estrato social (Organização Mundial da Saúde [OMS] (2011)). O decreto federal no 5.296 de 2 de dezembro de 2004 categoriza os tipos de deficiências em: física, auditiva, visual, intelectual e múltipla (associação de mais de um tipo de deficiência). O termo ao qual se refere à pessoa também houve substituição, onde ao invés de remeter à mesma como "deficiente", "portador de deficiência", "portadores de necessidades especiais", deve seguir a expressão consagrada pela Convenção sobre os Direitos das Pessoas com Deficiência: Pessoa com deficiência (PCD). Isso foi necessário para melhorar a compreensão que a pessoa está em primeiro lugar e que a deficiência é um produto das barreiras físicas, organizacionais e atitudinais presente na sociedade, as quais podem impedir sua plena inclusão e participação (Resende \& Vital, 2008; OMS, 2011).

A partir do censo realizado em 2010 pelo Instituto Brasileiro de Geografia e Estatística [IBGE], 45.606.048 de brasileiros, o que corresponde a cerca de 23,9 \% da população, possuem algum tipo de deficiência. Entretanto, em 2018, o IBGE fez uma releitura incorporando a linha de corte sugerida pelo Grupo de Washington de Estatísticas sobre Deficiência. Essa iniciativa foi necessária, pois muitas vezes confundem problemas de saúde com deficiência. Com a releitura, obteve um quantitativo de 12.748 .663 pessoas, ou 6,7\% do total da população em geral. Das pessoas investigadas: 3,4\% possui deficiência visual; $1,1 \%$ deficiência auditiva; $2,3 \%$ deficiência motora e 1,4\% deficiência intelectual. A faixa etária de 0 a 14 anos corresponde a $2 \%$ da população. Mesmo assim, a nota técnica desconsiderou algumas condições de transtornos mentais como autismo, neuroses, esquizofrenia e psicose, o que fragiliza a releitura no quesito promoção da equidade e de políticas exequíveis para o processo de ensino e aprendizagem para as PCD (IBGE, 2018).

Deficiência é comumente associada à incapacidade, o que reflete em consequências negativas como baixa autoestima, menor participação e maior estigmatização. Esses fatores podem gerar impactos sobre a educação e consequentemente na geração de emprego e renda (OMS, 2011). Os estigmas associados à PCD refletem em atitudes e ações irracionais e discriminatórias pelas pessoas consideradas normais, realçando a ideologia negativa de que PCDs são inferiores ou aberrações, e que não devem ter um destino agradável. Também estão associados à questão de aceitação, como nos casos em que a pessoa tenta corrigir algo inerente à sua condição a fim de se enquadrar aos padrões ditos "normais", o que reverbera a possível angústia por sua condição de saúde. Mas também diz respeito aos grandes esforços individuais em conquistar ações e espaços até então inimagináveis devido sua condição, rompendo barreiras do preconceito e impondo uma interpretação para sua identidade social (Goffman, 1988). De acordo com o Relatório Mundial Sobre a Deficiência, publicado pela Organização Mundial da Saúde (2011), os estigmas podem ser combatidos através de contato pessoal direto e marketing social.

A Lei Brasileira de Inclusão da Pessoa com Deficiência (2015), a qual busca a garantia dos direitos da PCD no país foi instituída com base na Convenção Internacional dos Direitos das Pessoas com Deficiência e tem como objetivo a inclusão social e cidadã da PCD. Dentre suas ações, assegurou a oferta de sistema educacional inclusivo em todos os níveis e modalidades de ensino, além de estabelecer a adoção de um projeto pedagógico que institucionalize o atendimento educacional especializado, com fornecimento de profissionais de apoio e a proibição das escolas particulares de cobrarem valores adicionais por esses serviços. Embora tenha a obrigatoriedade da lei, ainda é comum a existência de algumas barreiras escolares como: treinamento e suporte inadequados para professores, barreiras físicas, rotulagem, barreiras atitudinais, violência, bullying e abuso (OMS, 2011).

Os fatores comportamentais e ambientais têm impacto na participação e inclusão de PCD, visto que ambientes inacessíveis criam barreiras às vezes impossíveis de serem ultrapassadas. É importante destacar que fatores ambientais não querem dizer apenas o acesso físico, mas desde dispositivos que auxiliem à PCD, como por exemplo um intérprete de língua de sinais para pessoas surdas (OMS, 2011). 
Já a acessibilidade e o acesso são pressupostos fundamentais para garantir a facilidade em obter educação escolar. Para crianças com deficiência, assim como para qualquer criança, a educação é vital. Impedir sua participação escolar tem altos custos econômicos e sociais. A fim de evitar incapacidades, melhorar a saúde e garantir a inclusão no sistema educacional, deve-se elevar a conscientização, modificar o ambiente e fornecer instalações e serviços de apoio. Além disso, é importante que as crianças com deficiência sejam educadas em classes normais, com colegas que tenham faixa etária apropriada. Esse contato com outras crianças pode aumentar a familiaridade e reduzir preconceitos, tornando uma sociedade inclusiva e equitativa (OMS, 2011).

\section{Metodologia}

Este estudo de caso de abordagem qualitativa, descritiva e de natureza aplicada sobre pessoas com deficiência inseridas no ambiente escolar apoia-se na proposta elaborada por Berbel (1998) a qual propõe que a metodologia seja aplicada em questões relacionadas com a vida em sociedade a partir de cinco etapas: observação da realidade, pontos-chaves, teorização, hipóteses de solução e aplicação à realidade. Inseridos nas etapas da metodologia da problematização, este estudo traz como objetivos gerais (1) compreender porque as pessoas com deficiência são excluídas das práticas corporais no ambiente escolar e as possíveis teorias que justifiquem suas causas, (2) proporcionar o conhecimento acerca desse fenômeno e quais abordagens enfatizam a importância e (3) descrever possíveis abordagens com foco na dança para a promoção da inserção de PCD no ambiente escolar como propostas e soluções que visem a transformação estrutural.

\section{Fundamentação Teórico-Metodológica}

\section{Corporeidade e neurociência}

Partindo do conceito ampliado de percepção proposto por Merleau-Ponty (2018), trazida aqui como atitude corpórea, que envolve toda complexidade neuromotora, podemos elucidar acerca das demonstrações de afeto percebidas no decorrer das aulas de dança, advindas da percepção de atos e gestos do outro, como estimulantes da consciência do corpo e das possibilidades do mover-se dentro de um espaço-tempo.

A dança - como possibilidade de ação, percepção, compreensão e interpretação do movimento gestual - possibilita a corporeidade a partir da personificação do jogo simbólico como ferramenta para a expressão gestual. Desperta-se a sensibilidade estética, e o gesto, como leitura poética e plástica do corpo em movimento, firma-se numa dimensão peculiar do corpo em movimento, com o objetivo de promover a inferência emocional e a empatia, ou seja, a reação emocional dos sentimentos de outros (Koehne, Behrends, Fairhurst, \& Dziobek, 2016; Merleau-Ponty, 2018).

Embora o papel de como a imagem corporal e o movimento se processem ainda não esteja claro, estudos de neuroimagem demonstraram a ativação de estruturas substanciais para o aprendizado e o despertar de habilidades corporais (incluídas aqui funções cognitivas também) (Di Nota, Levkov, Bar, \& DeSouza, 2016; Koehne et al., 2016). O estudo de Di Nota et al. (2016) verificou que a prática da dança executa papel fundamental na interiorização do movimento que se dá seletivamente no córtex occipitotemporal lateral, no complexo occipital lateral e na área do corpo estriatal. Estas áreas são ativadas bilateralmente, tanto em bailarinos profissionais quanto em pessoas inexperientes em técnicas de dança. O papel destas áreas está na observação de sequências complexas de movimentos corporais.

Além disso, estudos recentes elencam a interferência cerebral global para explicar a capacidade inerente do ser humano em comunicar-se corporalmente. O núcleo córtico-talâmico encontra-se subjacente a aspectos conscientes da percepção, do pensamento, da aprendizagem, de sentimentos de conhecimento, de emoções sentidas, de imagens visuais, da memória operacional e do controle executivo (Leaver, Van Lare, Zielinski, Halpern, \& Rauschecker, 2009; Baars, Franklin, \& Ramsøy, 2013; Bieleninik et al., 2017; Teixeira-Machado, Arida, \& de Jesus Mari, 2019). 
Percepções sensoriais podem se interconectar e transmitir informações do córtex posterior, enquanto os sentimentos de conhecimento não sensoriais podem envolver áreas pré-frontais e frontotemporais. Córtex pré-frontal é responsável para iniciar o movimento. Já o córtex temporal medial contribui para a organização subjetiva do evento, bem como para a codificação de memória episódica. O complexo hipocampal parece estar envolvido na arquitetura da rede cerebral global, apoiando a organização de eventos conscientes, armazenamento de memória episódica e espaço-temporal, sendo essencial para eventos de antecipação e predição, além da intervenção do cerebelo nesse processo (Baars et al., 2013; Galvez-Contreras, Campos-Ordonez, Gonzalez-Castaneda, \& Gonzalez-Perez, 2017; Maffei, Herreros, Sanchez-Fibla, Friston, \& Verschure, 2017).

Estes estudos tem um papel impar na compreensão de como experiências perceptuais envolvem sentimentos do saber e de pertencimento. A proposição dinâmica do fazer corporal reflete o corpo no entorno, em contextos sociais, culturais e afetivos múltiplos. O corpo suporta-se numa consciência cognoscente, sempre referendada por um sujeito, mas apresenta-o na experiência do movimento (Jarvilehto, 1999). O ato de dançar então supera o limite da linearidade da comunicação. Quando nos movimentamos, há uma circularidade entre os acontecimentos do meio ambiente e os acontecimentos no próprio corpo, ocorrendo a aprendizagem, ou seja, uma nova interpretação desses acontecimentos. De certa forma, esses movimentos tornamse "automáticos", ou seja, tão logo os tenhamos aprendido, não precisamos mais "pensar sobre eles" para os executarmos. O conhecimento assim é incorporado. A cognição emerge da corporeidade, da experiência vivida e da capacidade do ser humano se movimentar. A cognição é inseparável do corpo (Amado, Sánchez-Miguel, \& Molero, 2017; Adamczyk et al., 2020).

Então, tais contextualizações do saber fazer do corpo inquirem a possibilidade de ser, mas não como 'este corpo que me pertence' ou 'este corpo que se move, age e fala', e sim advindo do próprio corpo tais contextualizações. O corpo não recebe o estatuto de um 'próprio', mas daquilo que é atuante pelas injunções que o colocam a falar, agir e se mover das maneiras específicas que o faz 'ser' (Foucault, 2009; Le Breton, 2016; Merleau-Ponty, 2018).

Dançar vai além disso. Ao considerar o uso do corpo em associação à música, o perceber-se dentro de um cenário estético desloca o papel da representação para o conhecimento incorporado. Refere-se ao fato de 'ser corpo', com uma infinidade de possibilidades sensório-motoras, imersas em contextos múltiplos, enfatizando a dimensão existencial do conhecer, emergido da corporeidade.

\section{Proposta pedagógica de dança para PCD}

Para alguns educadores, a aprendizagem só acontece quando o aluno está sentado e quieto, entretanto o aluno pode não estar satisfeito com sua inquietude pois é insuportável permanecer por muito tempo em uma mesma posição. A dança na sala de aula quando integrada com outras disciplinas, na medida que favorece a criatividade, pode contribuir com o processo de aprendizagem por quebrar esse 'padrão de quietude' (Scarpato, 2001).

A sistematização da nossa proposição baseia-se nas concepções propostas por Dalcroze, Feldenkrais, Laban e Pilates. Programas que visem a prática corporal de dupla tarefa e multidimensional são desafiadores, motivadores e fáceis de executar. Dançar, além de contribuir para a autoestima, a autoconfiança e o bem-estar, pode auxiliar na diminuição de dores, aumento de amplitude de movimento, mudanças na emoção, no estado de consciência, além de promover saúde e consciência corporal (Adamczyk et al., 2020; Teixeira-Machado \& DeSantana, 2019; Teixeira-Machado et al., 2019; Ferguson-Stegall, Vang, Wolfe, \& Thomsen, 2017).

Jaques-Dalcroze propôs um programa de exercícios de multitarefa através do uso da música e do corpo, que estimulam funções motoras e cognitivas, além do engajamento da atenção e das funções executivas, convertendo o sentido rítmico numa experiência corporal. Dalcroze Eurhythmics é um processo para despertar, desenvolver e refinar a musicalidade inata humana através do ritmo do movimento, treinamento auditivo e improvisação que focaliza a consciência nas demandas 
físicas da performance artística, dividida em três eixos: ritmo, treinamento auditivo e improvisação. Outro aspecto importante da Dalcroze Eurhythmics é o trabalho em grupo, incluindo as interações mútuas entre os membros do grupo. A intenção de Jaques-Dalcroze era desenvolver um senso de identidade, bem como um senso de sociabilidade por meio das atividades corporais rítmicas propostas (Adamczyk et al., 2020; Ferguson-Stegall et al., 2017; Madureira \& Banks-Leite, 2010).

O Método Feldenkrais também parte da perspectiva que se deve educar o corpo para se mover em infinitas maneiras possibilitando o potencial humano de aprender a aprender. Moshé Feldenkrais sistematizou processos de exploração corporal baseados em movimentos e sensações. As explorações baseiam-se em praticar processos não lineares de sentir a diferença entre duas ou mais opções para realizar a tarefa de movimento declarada e fazer um discernimento sobre qual pode parecer mais fácil, isto é, executada com menos esforço. Esses discernimentos perceptivos são baseados em um julgamento que é positivo (prazeroso, fácil e com menos esforço) em comparação com a experiência de um sinal de feedback menos favorável, como dor, tensão ou desconforto. Assim, o processo de intenção, ação, obtenção de feedback, tomada de decisões e criando as adaptações para o movimento constituem a estrutura de aprendizagem em um contexto somático (Lee, 2018; TeixeiraMachado et al., 2015; Connors, Galea, Said, \& Remedios, 2010).

A proposta de Rudolf Laban sistematiza que os alunos devem expor seus próprios movimentos, considerando a integração de corpo e mente, demonstrando a importância de respeitar o ritmo de cada um. O dançar na escola não deve impor um padrão técnico de perfeição com beleza das linhas e leveza dos movimentos, e sim deixar livre a expressão do aluno, a fim de torná-lo um cidadão crítico, participativo e responsável (Scarpato, 2001). A análise do movimento de Laban classifica os componentes do movimento em quatro categorias principais: Corpo, Esforço, Espaço e Forma. Os componentes dessas categorias mudam durante o movimento em tempo real, de acordo com os níveis planares (baixo, médio e alto), as direções (frente, trás, lado, diagonal, círculo) e os quatro fatores de movimento: espaço (longo/curto), tempo (rápido/lento), fluência (contínua/cortada) e peso (leve/pesado) (Bernardet et al., 2019).

Há relatos que Laban integrou exercícios do método Pilates em suas aulas. Assim como na dança, o método Pilates faz uso de todos os planos de movimento do corpo de forma simultânea, conectando estruturas, níveis e sistemas corporais. É uma proposta que foca menos nos grupos musculares isolados, dando ênfase no trabalho do corpo todo associado à respiração, visto que a mesma leva a eficiência do movimento. Joseph Pilates enfatizava que a mente e o corpo precisam estar coordenados para obter máximo rendimento, que um não pode ser supremo ao outro. O método segue seis princípios fundamentais para melhor aproveitamento durante sua prática, são eles: concentração, centralização, controle, fluidez, precisão e respiração, os quais devem em todo momento estarem conectados, tornando assim, um movimento com qualidade e prazeroso (Ahearn, 2006; Pilates, 2011; Bolsanello, 2015).

Baseado nos conceitos citados acima, utilizamos uma proposta que consiste em aulas de dança com duração de uma hora, duas vezes por semana para PCDs chamada Técnica Aplicada Lavinia Teixeira (TALT). Os exercícios se concentram na amplitude de movimento global, coordenação motora, imagem corporal, habilidade e agilidade. Nossas aulas baseiam-se em três componentes fundamentais para a educação corporal através da dança: o eu, o ambiente, e o outro. Detalhes na Figura 1. 
Figura 1: Componentes norteadores do protocolo específico de dança para pessoas com deficiência.

\section{Protocolo de Dança (TALT)}

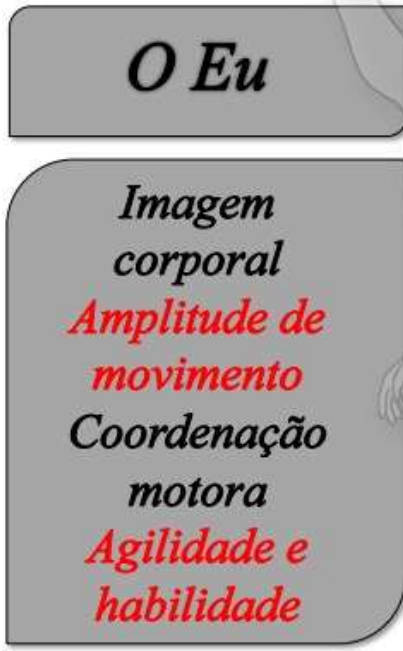

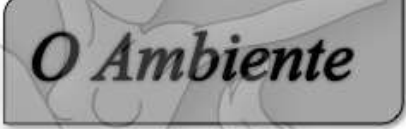

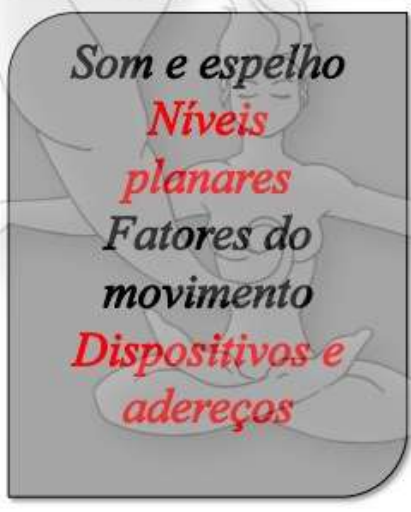

Fonte: Autores.

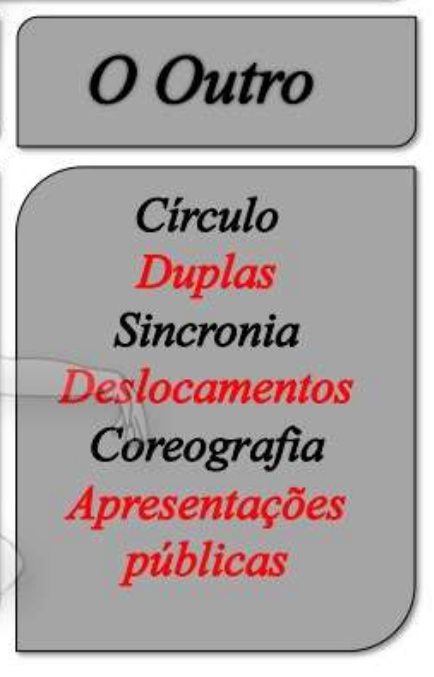

Circulo

Sincronia

Deslocamentos

Coreografia

públicas

$O \mathrm{eu}$ : as práticas que compõem este eixo, baseiam-se no corpo além do biológico. A consciência e a imagem corporal (a representação mental, abrangendo aspectos afetivos, cognitivos e sociais) são fatores substanciais para a corporeidade. Segundo DeJesus e colaboradores (2021), além da representação mental, os componentes relacionados à amplitude dos movimentos realizados (representados pelos planos e eixos de movimento para o uso do corpo em toda sua amplitude angular permitida), à coordenação motora (através de interações bilaterais implícitas em movimentos visomotores) e à habilidade e agilidade dos movimentos (ou seja, na execução de movimentos variados bilateralmente, explorando mecanismos de coordenação motora e estabilidade corporal e postural, com atividade simultânea de segmentos com e sem alternância de membros superiores e inferiores) também compõem esse eixo (Teixeira-Machado, 2015; Teixeira-Machado, Azevedo-Santos, \& DeSantana, 2017; Teixeira-Machado \& DeSantana, 2019). Como proposto por DeJesus e colaboradores (2021), para que possamos acionar os componentes de imagem corporal, amplitude de movimento, coordenação motora e agilidade dos movimentos, cada aula de dança deve compor:

(1) os níveis planares propostos por Laban (baixo, médio e alto);

(2) os quatro fatores de movimento: espaço (longo/curto), tempo (rápido/lento), fluência (contínua/cortada) e peso (leve/pesado);

(3) os deslocamentos durante os passos de dança acontecem para todas as direções (frente-trás, lado-lado, em círculo e para as diagonais), e o uso de dispositivos e adereços que ampliam a comunicação em dança, como pandeiros, chocalhos, tecidos.

O controle motor, a amplitude de movimento, a coordenação e habilidade motoras são essenciais para a execução dos movimentos, porém destacamos o papel essencial da corporeidade para a construção de um movimento intencional desejado, independentemente das limitações biológicas, sejam elas físicas, sensoriais, intelectuais ou múltiplas.

Em relação ao ambiente, a adoção de fatores filosóficos e metodológicos são determinantes para transferir o olhar da incapacidade e da doença, para a capacidade do indivíduo em se relacionar com o seu ambiente, transferindo do indivíduo a incapacidade de mobilidade, e centrando o enfoque no espaço vivenciado pela PCD. A Classificação Internacional de 
Funcionalidade, Incapacidade e Saúde (CIF), divulgada pela OMS em 2001, analisa a saúde dos indivíduos a partir de cinco categorias: funcionalidade, estrutura morfológica, participação na sociedade, atividades da vida diária e o ambiente social de cada pessoa (OMS, 2011). Tal percepção traz maior clareza sobre a qualidade do funcionamento das ações específicas e dos efeitos sobre a inserção das pessoas com deficiência, permitindo descrever situações relacionadas com a funcionalidade do ser humano e suas restrições. O ambiente em que o aluno que tenha algum tipo de deficiência está inserido deve preconizar os princípios da mobilidade e da acessibilidade, mitigando as barreiras que dificultam o livre acesso nos espaços urbanos e rurais. A sala de aula é o disparador inicial do processo de aprendizagem em dança. Ela deve ter piso apropriado, espelho e aparelhagem de som. De preferência, não devem conter muitas informações sensoriais na sala, como ruídos, barulhos, cores fortes nas paredes, quadros, luminárias, dentre outros dispositivos que possam tirar o foco atencional na aula de dança. Os espaços para exposições coreográficas serão os mais diversos e o aluno deve ser preparado para a apresentação artística, levando em consideração o figurino, o cenário e a plateia (Teixeira-Machado, 2015; Teixeira-Machado, Azevedo-Santos, \& DeSantana, 2017; Teixeira-Machado \& DeSantana, 2019; DeJesus et al., 2021).

O outro: este eixo visa aprimorar a relação com o outro, com os outros. A educação planejada para o século XXI se fortalece através de práticas pedagógicas que trabalham com o afetivo, o cognitivo, o social e o motor. O processo de ensinoaprendizagem deve ser alicerçado em quatro pilares bem definidos, o aprender a: ser, conviver, fazer e conhecer (Pantaleão, 2019). O processo educacional abarca uma multiplicidade de interpretações, vertentes e interesses que na maioria das vezes são divergentes para que a inclusão de fato se proceda nos ambientes escolares, embora as discussões acerca de questões sociais, com conceitos, práticas e metodologias próprias, que, por sua vez, não são facilmente evidentes e exequíveis (Layrargues \& Lima, 2011). Por exemplo, o posicionamento dos integrantes da aula de dança dispostos em círculo, em duplas, em grupos, viabiliza experiências interpessoais e o diálogo intercorpóreo. DeJesus et al. (2021) reforçam que a atitude incorporada durante os duetos de dança é tomada como exemplo de sintonia não verbal ativa entre os parceiros durante a interação performática. As montagens coreográficas acionam o senso de intersubjetividade e diferenciação do eu e do outro, através de estruturas de movimento compartilhado e sincronizado. E não podemos deixar de destacar o papel essencial das apresentações públicas que reverberam a natureza de um sujeito estar no mundo com outros e de ser percebido como centro de expectação daqueles que não vivenciaram suas experiências durante as aulas de dança (Teixeira-Machado, 2015; Teixeira-Machado, Azevedo-Santos, \& DeSantana, 2017; Teixeira-Machado \& DeSantana, 2019; DeJesus et al., 2021). Além disso, reforça o sentimento de pertencimento, e a inclusão da diversidade humana se estabelece. Fato que contribui para as importantes propriedades do engajamento e da motivação, que podem ser tomados como um fenômeno de dois lados entre o indivíduo e o outro/outros, os quais influenciam sobremaneira o ser social, inserido no contexto do qual, na maioria das vezes, está à margem, sem noção de que suas ações podem ser refletidas no outro.

Então, além dos três componentes norteadores, as aulas de dança realizadas por meio deste protocolo específico, deve utilizar canções e performances que estimulem o brincar imaginário, fundamentais para o desenvolvimento da comunicação e da reciprocidade social, com vistas ao movimento expressivo, que se estabelece na empatia cinestésica provocada pela ressonância corporal que se configura através da sincronização do movimento com o outro e da sintonia corpo-performance (Figura 2).

A empatia cinestésica acontece através da imitação por espelhamento de qualidades de movimento e formas. Embora a dança seja tradicionalmente entendida como uma forma de auto-expressão do corpo no espaço para fins artísticos e visto por um público, Basso, Satyal e Rugh (2021) apoiam a hipótese de que as pessoas que dançam são engajadas por um princípio de recompensa intrínseca que aprimora a coordenação interpessoal. A esse processo poderíamos sugerir que a empatia é potencializada pela ressonância corporal mediante a coordenação intra e interpessoal que pode ser redefinida pela experiência compartilhada de dançar junto, é o ajuste de dois corpos, momento a momento, por processo bilateral durante a dança, seja 
face a face, sejam os corpos refletidos no espelho, ou todos num palco frente a uma plateia atenta. Sintonização/sintonia: visa estabelecer formas de intersubjetividade, que é a incorporação da expressão corporal que dança pra si ou pra outros, ou com outros, juntos, sincronizados ou não; a sintonização da música com o que de fato se quer expressar; a sintonização dos adereços em cena, do outro, do ambiente. Essa sintonização intrínseca do comportamento humano surge ainda no feto e está presente em todas as culturas. Esta "afinação" corpo-movimento-percepção está também relacionada a experiência de aprazimento, deleite, contentamento (Zentner \& Eerola, 2010; Fujii et al., 2014; Trehub \& Cirelli, 2018). Quando alguém vê um corpo que dança, ou quando ouve uma música, o corpo é levado a se mover em sintonia ou se conectar à sintonia de notas, timbres, batidas, movimentos, que se configura ao arrebatamento rítmico disparado por estados emocionais e afetivos positivos (Basso et al., 2021).

Figura 2: Componentes essenciais para a sistematização das aulas pelo protocolo de dança específico para pessoas com deficiência.

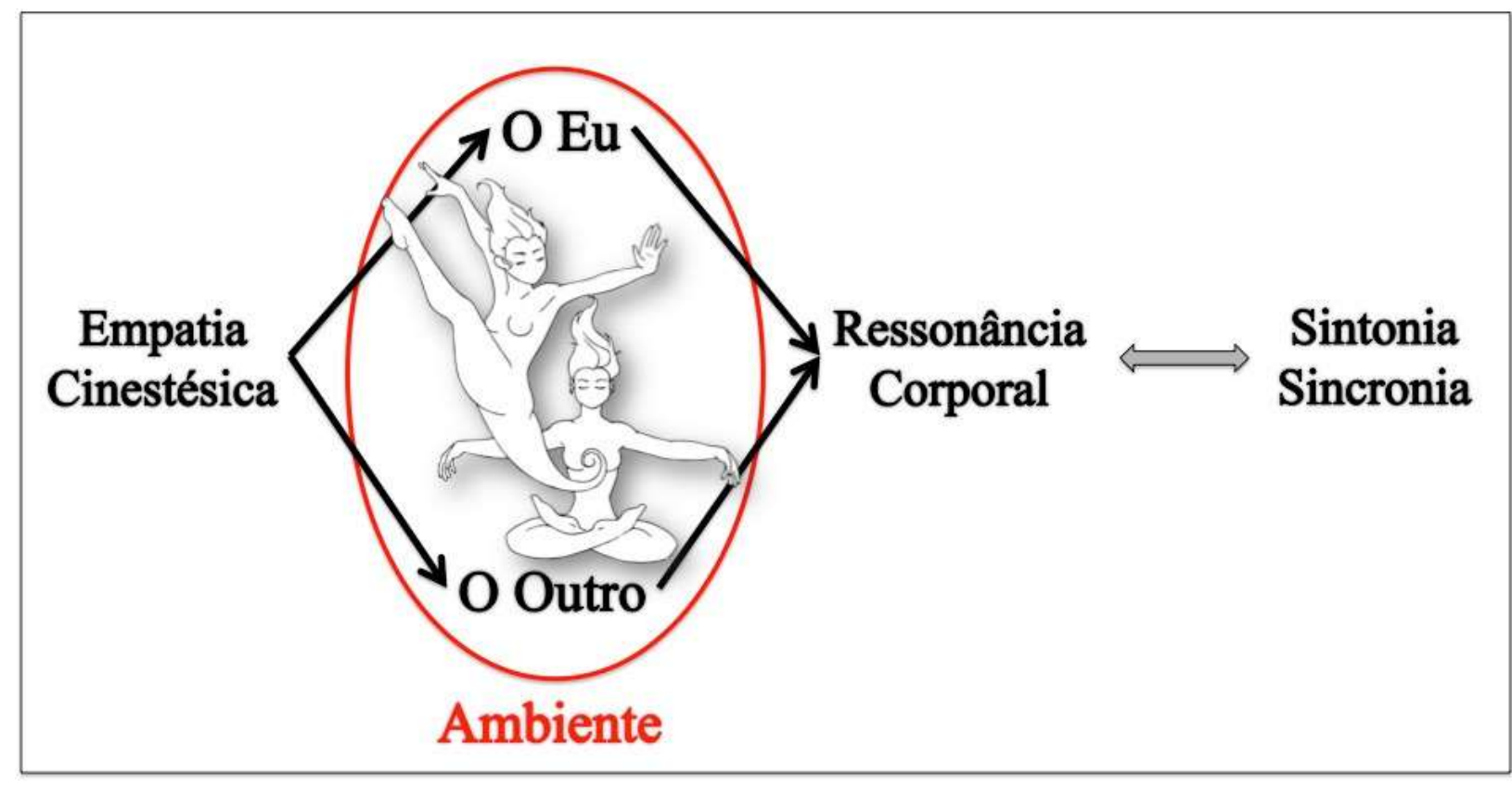

Fonte: Autores.

\section{Corpo, dança, deficiência e sociedade}

A dança é encontrada em todas as culturas e cria oportunidades para movimento funcional nas diversas condições da PCD por ser uma atividade corporal aprimorada que estimula a participação e o engajamento pessoal e do grupo, isso porque envolve expressão individual e expressão social. Pesquisas recentes em dança no transtorno do espectro do autismo (DeJesus et al., 2020; Mastrominico et al., 2018; Souza-Santos, dos Santos, Azevedo-Santos, \& Teixeira-Machado, 2018), na síndrome de Down (Dipasquale, Canter, \& Roberts, 2020; McGuire, Long, Esbensen, \& Bailes, 2019; Gutiérrez-Vilahú, MassóOrtigosa, Costa-Tutusaus, Guerra-Balic, \& Rey-Abella, 2016), e na paralisia cerebral (Teixeira-Machado, Azevedo-Santos, \& DeSantana, 2017; López-Ortiz, Gaebler-Spira, Mckeeman, Mcnish, \& Green, 2019) tem demonstrado que a prática da dança contribui para a aptidão e o desenvolvimento do sistema neuropsicomotor, que abrangem o paradigma da CIF, no que concerne ao bojo da função humana na capacidade de se viver em sociedade, de acordo com as estruturas e funções corporais, atividade, participação, fatores ambientais e fatores pessoais. Nessa linha, a dança também pode ajudar a aprimorar as habilidades de comunicação não verbal dentro das músicas usadas durante as aulas, que tem a capacidade de despertar a expressão facial, o comportamento social e o reconhecimento de emoções por meio da sincronização do movimento. As funções expressivas do 
corpo por meio da dança atuam diretamente na comunicação, o que pode influenciar o processo de transmitir sentimentos internos ao meio externo, o que evidencia a influência da dança na comunicação (DeJesus et al., 2020; DeJesus et al., 2021).

Estudos tem mostrado que a dança também está associada a um sentimento de proximidade do outro e de um comportamento pró-social. Mastrominico e colaboradores (2018) relataram sobre a influência da dança na comunicação em relação à emoção, empatia, percepção e expressão corporal. Souza-Santos et al. (2018) destacam que a dança pode atuar no engajamento da participação social, incluindo o relacionamento e a comunicação dos participantes com TEA.

É importante ressaltar que a interação social é um grande desafio das PCDs, pois afeta o relacionamento com familiares, amigos e comunidade, impactando fortemente a autoestima e a independência social. Por conta disso, o espelho é constantemente explorado durante as aulas de dança para despertar a imitação do movimento, das coreografias, das sequências, o que pode contribuir para aumentar a consciência corporal, as habilidades sociais, a distinção self-other, a empatia. A capacidade de interagir socialmente é um objetivo direto nosso, através do desenvolvimento de competências não verbais, que geram autonomia, autoconfiança e autoestima. Outro ponto essencial a ser destacado é o estímulo ao contato visual durante a ação em dança, outra conexão corporal por sintonia e sincronia, e os sentimentos e significados emergentes nas canções. É uma visão poética de ver o mundo exterior e desencadeia o processo de usar suas mentes para considerar ou raciocinar sobre si mesmas e o ambiente.

A injustiça ambiental pode ser descrita como o tratamento díspar de determinado grupo ou comunidade com base na raça, classe, ou outra característica distintiva. Vale ressaltar a grande diversidade das pessoas na aparência, no comportamento, que ultrapassam a cultura e os costumes. As singularidades do modo de vida é o que define a distinção entre as pessoas, mediante as particularidades biológicas, psicológicas e socioculturais. Todavia, diferença não é sinônimo de distinção hierárquica. De acordo com De Sousa Santos (2020), PCD têm sido vítimas de diversas formas de dominação, além do capitalismo, do colonialismo e do patriarcado: o capacitismo. Trata-se da forma como a sociedade os discrimina, não lhes reconhecendo as suas necessidades, não lhes facilitando acesso à mobilidade e às condições que lhes permitam desfrutar da sociedade como qualquer outra pessoa. De algum modo, as limitações que a sociedade lhes impõe fazem com que se sintam a viver em quarentena permanente.

Ao analisar o contexto da diversidade e das diferenças humanas, é mister sinalizar o foco de atenção para a forma como os seres humanos lidam com elas. A verdade é que não estamos acostumados "com o diferente". Remete algo que pode causar singularidade, incomodidade. Pode-se dizer que, muitas vezes, não é o fato da diferença que causa a estranheza, mas a expectativa de romper com o esperado, a quebra de expectativa. Sabe-se que a diversidade faz parte da natureza humana e a deficiência é mais uma viabilidade de diferença entre os seres humanos. A PCD encontra-se no grupo do diferente, talvez tenha suas diferenças mais perceptíveis, já que pode possuir sinais ou sequelas mais notáveis (Reis, 2016).

Sendo assim, no decorrer da história humana, foram diversas as maneiras assumidas pela sociedade em relação aos grupos minoritários. Tais atitudes foram se alterando por influência de fatores econômicos, culturais, filosóficos e científicos. Dependendo das condições vividas em relação a contextualizações políticas, econômicas ou religiosas, a sociedade em questão considerava as PCD como detentoras de bons ou maus espíritos. Dessa forma, as PCD foram tratadas de forma diferenciada, pois estavam sujeitas ao espírito do seu tempo, podendo ser enaltecidas, segregadas ou descartadas.

O exercício incessante da conquista da alteridade e da individualidade favorecem o processo de demarcação da PCD perante a sociedade, a identidade que é construída através de experiências socioculturais. As relações da pessoa com o ambiente, com a comunidade, formam um amálgama de axiomas que configuram padrões regulatórios excludentes. Pessoas delimitadas num processo histórico cultural de que PCD não têm capacidade de escolhas, e apresentam contexto biopsicossocial fragilizado acerca das possibilidades potenciais de agir e interagir no meio em que vivem.

Talvez por impossibilidade de utilização dos espaços urbanos e rurais, a falta de acesso a informações, as barreiras 
atitudinais e comunicacionais, dificultam as potencialidades da PCD explorar os espaços ao seu redor. Oferecer no ambiente escolar propostas educacionais que fomentem a suplantação de estigmas culturais existentes, fornecem valorização e visibilidade da PCD num sentido mais amplo à inclusão social, significa possibilitar a elas, o respeito às necessidades próprias da sua condição, o acesso aos serviços, aos bens culturais e aos produtos decorrentes do avanço social, político, econômico e tecnológico da sociedade.

Nesta linha, a inserção da PCD nos contextos sociais, assim como no ambiente escolar, viabiliza a concepção de "ser parte de um todo", mas não no sentido discriminativo ou estigmático, e sim num sentido de pertencimento, num lugar que lhe é conferido mediante as implicações étnicas, políticas, epistemológicas e metodológicas que não determinam a sua exclusão em nenhum espaço.

É nesta concepção que a prática da dança infere papel transformador tanto para a PCD quanto para o ambiente que está inserida, com identidade singular, que necessita ser respeitada e vista. A prática da dança permite a "abertura" do ser no mundo ao se perceber partícipe dos fenômenos sociais, que propõe o entendimento das diferenças entre as pessoas, numa tendência à expansão dos padrões biológicos, culturais, e políticos com vistas à alteridade.

Todo ser humano, com raras exceções, percebe e interioriza ritmo e música, além da linguística. Ao sentir sons, timbres, notas, o corpo humano tende a sincronizar internamente esse ritmo. Porque o corpo é esmeradamente sintonizado para o movimento intencional e emocional. Mesmo em pessoas que sofreram lesões cerebrais ou apresentam alterações na circuitaria de associação sensorial e perceptiva, pesquisas tem mostrado que a prática da dança, a partir do movimento pela dança, paulatinamente modifica-se a conectividade cerebral e permite que o movimento aconteça (Sacks, 2006; TeixeiraMachado, Arida, \& de Jesus Mari, 2019).

No que concerne ao pilar pedagógico, podemos sugerir que a prática da dança no ambiente escolar pode contribuir para o aprimoramento neuromotor, cognitivo, emocional e social. No âmbito da viabilização do aprimoramento neuromotor, os movimentos dançados acionam a função semiestática e dinâmica corporal, assim como a promoção da funcionalidade e da mobilidade articular e muscular (Teixeira-Machado, Azevedo-Santos, \& DeSantana, 2017; Teixeira-Machado \& DeSantana, 2019). No âmbito dos processos cognitivos, a dança, a partir da elaboração do movimento intencional, fomenta a conectividade cerebral a partir do logos estético que amplia a percepção e a capacidade de mover-se além do aparentemente permitido (Teixeira-Machado, Arida, \& de Jesus Mari, 2019). Em relação ao estado emocional, a prática da dança permite a participação em atividades socioculturais que motivam a realização dos passos de dança, em grupo, num palco, fato que desencadeia processos emocionais que evocam o sentimento de pertencimento (Amado et al., 2017).

É nesse âmbito que salientamos o corpo da pessoa com deficiência, que também é um corpo social, e que também é vestido de sua subjetividade. E, com ela, com a consciência do ser parte de um todo, a PCD é capaz de transpor o estigma da invisibilidade e da incapacidade. Ao se perceber no outro que o vê mediante a representação artística que lhe transveste, favorecendo a construção de uma identidade singular que se transforma junto com o ambiente que está inserido, prolongando para a sociedade. Esse despertar do corpo que dança, junto com outros corpos, tenham deficiência ou não, possibilita a comunicação e a libertação de padrões que se reajustam à nova disposição de dançar (Amado et al., 2017; Schroeder et al., 2017). Isto porque estratégias educacionais que focam no aprendizado cinestésico, e quando somada a ação com o outro, favorecem a motivação incorporada, por ser orgânico e natural, divergindo de padrões que lenificam a corporeidade. A educação pela dança no ambiente escolar solidifica a integração de vários sistemas, como o visual, o auditivo e o cinestésico, ao compreender que o movimento expressivo facilita a compreensão e a interiorização do mover-se em dança (Gujing et al., 2019).

O ajustamento corporal pode então ser explorado e vislumbrado pela consciência da percepção de sons, timbres, compassos que se reverberam nas performances que a PCD impacta na sociedade: a expressão artística é ímpar e desperta 
estímulos sociais num patamar avassalador antes visto com estranheza, desempenha papel substancial na maturação e modificação da educação ao parafrasear Paulo Freire:

[...] acreditamos que a educação sozinha não transforma a sociedade, sem ela tampouco a sociedade muda. Se a nossa opção é progressiva, se estamos a favor da vida e não da morte, da equidade e não da injustiça, do direito e não do arbítrio, da convivência com o diferente e não de sua negação, não temos outro caminho se não viver a nossa opção. Encarná-la, diminuindo, assim, a distância entre o que dizemos e o que fazemos (Freire, 2000, p. 67).

Numa visão mais ampliada, a dança para pessoa com deficiência no ambiente escolar pode ser vista como uma possibilidade de prática baseada na evidência de procedimentos técnicos e científicos para produzir uma ação transformadora sobre o corpo e o meio físico que este corpo atua, respondendo a exigências individuais que se definem à margem da própria técnica, dentro de um contexto de organização de práticas sociais, econômicas, políticas e ideológicas nas quais se inclui.

\section{Considerações Finais}

Então, a educação corporal através da dança elenca o entendimento da importância da corporeidade para o estabelecimento do arcabouço neuropsicomotor advindo dela e da interiorização de como o corpo se comporta socialmente. Interagir socialmente pela dança não se limita ao mundo simbólico, mas constrói a comunicação e a inter-influenciação de duas ou mais pessoas. A socialização então se alicerça na relação interpessoal evocada pela empatia e pela reciprocidade social que cada um expõe das suas próprias ações, e, assim, regulam o 'eu' num 'nós' construído socialmente. O 'somos' é, ao mesmo tempo, psicológico e social, num entrelaçamento natural, afetivo e simbólico.

A conexão da realidade sensível, na dimensão poética da corporeidade se expressa através desse gesto dançado, e então não se deixa apreender numa perspectiva reducionista da intelecção, do pensamento, já que ela emerge de processos corporais, ou seja, de significações vividas e não da ordem do 'eu penso', pois esse pensar é corpóreo. Podemos então inferir que a dança permite dialogar entre motricidade e funções simbólicas, que não se separam pelo entendimento, pois entrelaçamse na reversibilidade dos sentidos de uma dimensão estética. A partir deste estudo, entendemos que a experiência estética da dança amplia a operação expressiva do corpo e a percepção, afinando os sentidos, aguçando a sensibilidade, elaborando a linguagem, a expressão e a comunicação, proporciona à PCD ser, de fato, um ator coletivo e social, ao fomentar meios substanciais para a integração emocional, cognitiva, física e social no ambiente escolar.

Em suma, nossa proposição espera contribuir para o desenvolvimento de pesquisas futuras que busquem a institucionalização de propostas de práticas corporais na ambiência educacional, as quais visem a articulação entre as diferentes atividades curriculares, considerando esta estratégia necessária para mitigar o estigma e a discriminação de pessoas com deficiência.

\section{Agradecimentos}

O presente trabalho foi realizado com apoio da Coordenação de Aperfeiçoamento de Pessoal de Nível Superior Brasil (CAPES) - Código de Financiamento de AAP: 88887.512294/2020-00 e de LTM: 400075/2017-2.

\section{Referências}

Adamczyk, J., Celka, R., Stemplewski, R., Ceynowa, K., Kamińska, P., \& Maciaszek, J. (2020). The Impact of 12-Week Jaques-Dalcroze Eurhythmics Programme on the Dynamic Agility in Single-Dual-Task Conditions in Older Women: A Randomized Controlled Trial. BioMed Research International, 2020.

Ahearn, E. L. (2006). The Pilates method and ballet technique: applications in the dance studio. Journal of Dance Education, 6(3), 92-99.

Amado, D., Sánchez-Miguel, P. A., \& Molero, P. (2017). Creativity associated with the application of a motivational intervention programme for the teaching of dance at school and its effect on the both genders. PLoS one, 12(3), e0174393. 
Baars, B. J., Franklin, S., \& Ramsøy, T. Z. (2013). Global workspace dynamics: cortical "binding and propagation" enables conscious contents. Frontiers in psychology, 4, 200

Basso, J. C., Satyal, M. K., \& Rugh, R. (2021). Dance on the Brain: Enhancing Intra-and Inter-Brain Synchrony. Frontiers in Human Neuroscience, $14,586$.

Berbel, N. A. N. (1998). A problematização e a aprendizagem baseada em problemas: diferentes termos ou diferentes caminhos?. Interface-Comunicação, Saúde, Educação, 2, 139-154.

Bernardet, U., Fdili Alaoui, S., Studd, K., Bradley, K., Pasquier, P., \& Schiphorst, T. (2019). Assessing the reliability of the Laban Movement Analysis system. PloS one, 14(6), e0218179.

Bieleninik, Ł., Geretsegger, M., Mössler, K., Assmus, J., Thompson, G., Gattino, G., \& TIME-A Study Team. (2017). Effects of improvisational music therapy vs enhanced standard care on symptom severity among children with autism spectrum disorder: the TIME-A randomized clinical trial. Jama, 318(6), $525-535$.

Bolsanello, D. P. (2015). Is Pilates a Somatic Education Method?. Revista Brasileira de Estudos da Presença, 5(1), 101-126.

Connors, K. A., Galea, M. P., Said, C. M., \& Remedios, L. J. (2010). Feldenkrais Method balance classes are based on principles of motor learning and postural control retraining: a qualitative research study. Physiotherapy, 96(4), 324-336.

De Sousa Santos, B. (2020). A cruel pedagogia do vírus. Boitempo Editorial.

DeJesus, B. M., Oliveira, R. C., de Carvalho, F. O., de Jesus Mari, J., Arida, R. M., \& Teixeira-Machado, L. (2020). Dance promotes positive benefits for negative symptoms in autism spectrum disorder (ASD): a systematic review. Complementary therapies in medicine, 49, 102299.

DeJesus, B. M., Passos, A. A., Menezes, E. O., Adorno, E. T., DeSantana J. M., \& Teixeira-Machado L. (2021). Incorporation of dance practice into the lifestyle of people with disabilities and its impact on quality of life over time. Phys Med Rehabil Int., 8(2), 1178.

Di Nota, P. M., Levkov, G., Bar, R., \& DeSouza, J. F. (2016). Lateral occipitotemporal cortex (LOTC) activity is greatest while viewing dance compared to visualization and movement: learning and expertise effects. Experimental brain research, 234(7), 2007-2023.

Dipasquale, S., Canter, B., \& Roberts, M. (2020). Integrative Dance for Adults with Down Syndrome: Effects on Postural Stability. International Journal of Exercise Science, 13(3), 1317.

Ferguson-Stegall, L., Vang, M., Wolfe, A. S., \& Thomsen, K. M. (2017). A 9-week Jaques-Dalcroze eurhythmics intervention improves single and dual-task gait speed in community-dwelling older people. Journal of physical activity and health, 14(9), 740-744.

Foucault, M. (2009). Vigiar e punir: nascimento da prisão (36 ed.). Tradução de Raquel Ramalhete. Vozes.

Freire, A. M. A. (2000). Pedagogia da indignação: cartas pedagógicas e outros escritos. UNESP.

Fujii, S., Watanabe, H., Oohashi, H., Hirashima, M., Nozaki, D., \& Taga, G. (2014). Precursors of dancing and singing to music in three-to four-months-old infants. PloS one, 9(5), e97680.

Galvez-Contreras, A. Y., Campos-Ordonez, T., Gonzalez-Castaneda, R. E., \& Gonzalez-Perez, O. (2017). Alterations of growth factors in autism and attention-deficit/hyperactivity disorder. Frontiers in psychiatry, 8, 126.

Goffman, E. (1988). Estigma: notas sobre a manipulação da identidade. Tradução: Mathias Lambert, 4.

Gujing, L., Hui, H., Xin, L., Lirong, Z., Yutong, Y., Guofeng, Y., \& Dezhong, Y. (2019). Increased insular connectivity and enhanced empathic ability associated with dance/music training. Neural plasticity, 2019.

Gutiérrez-Vilahú, L., Massó-Ortigosa, N., Costa-Tutusaus, L., Guerra-Balic, M., \& Rey-Abella, F. (2016). Comparison of Static Balance on a Platform in Young Adults With Down Syndrome Before and After a Dance Program. Adapted physical activity quarterly: APAQ, 33(3), $233-252$.

Instituto Brasileiro de Geografia e Estatística (2018). Nota técnica 01/2018: Releitura dos dados de pessoas com deficiência no Censo Demográfico 2010 à luz das recomendações do Grupo de Washington. Brasília: IBGE.

Instituto Brasileiro de Geografia e Estatística. Censo Demográfico. http://www. censo2010. ibge. gov. br/>.

Jarvilehto, T. (1999). The theory of the organism-environment system: III. Role of efferent influences on receptors in the formation of knowledge. Integrative Physiological and Behavioral Science, 34(2), 90-100.

Koehne, S., Behrends, A., Fairhurst, M. T., \& Dziobek, I. (2016). Fostering social cognition through an imitation-and synchronization-based dance/movement intervention in adults with autism spectrum disorder: A controlled proof-of-concept study. Psychotherapy and psychosomatics, 85(1), 27-35.

Layrargues, P. P., \& Lima, G. F. D. C. (2011). Mapeando as macro-tendências político-pedagógicas da educação ambiental contemporânea no Brasil. Encontro Pesquisa em Educação Ambiental, 6, 1-15.

Le Breton, D. (2016). O inapreensível do corpo. Antropologia do corpo. (4a ed.). Vozes, 15-34.

Leaver, A. M., Van Lare, J., Zielinski, B., Halpern, A. R., \& Rauschecker, J. P. (2009). Brain activation during anticipation of sound sequences. Journal of neuroscience, 29(8), 2477-2485.

Lee, C. (2018). Musicians as movers: Applying the Feldenkrais method to music education. Music Educators Journal, 104(4), 15-19. 
Lei $\mathrm{n}^{\circ}$ 13.146, de 6 de julho de 2015. Institui a Lei Brasileira de Inclusão da Pessoa com Deficiência (Estatuto da Pessoa com Deficiência). Recuperado de http://www.planalto.gov.br/ccivil_03/_ato2015-2018/2015/lei/113146.htm.

López-Ortiz, C., Gaebler-Spira, D. J., Mckeeman, S. N., Mcnish, R. N., \& Green, D. (2019). Dance and rehabilitation in cerebral palsy: a systematic search and review. Developmental medicine \& child neurology, 61(4), 393-398.

Madureira, J. R., \& Banks-Leite, L. (2010). Jaques-Dalcroze: música e educação. Pro-Posições, 21(1), 215-218.

Maffei, G., Herreros, I., Sanchez-Fibla, M., Friston, K. J., \& Verschure, P. F. (2017). The perceptual shaping of anticipatory actions. Proceedings of the Royal Society B: Biological Sciences, 284(1869), 20171780.

Mastrominico, A., Fuchs, T., Manders, E., Steffinger, L., Hirjak, D., Sieber, M., \& Koch, S. C. (2018). Effects of dance movement therapy on adult patients with autism spectrum disorder: A randomized controlled trial. Behavioral Sciences, 8(7), 61.

McGuire, M., Long, J., Esbensen, A. J., \& Bailes, A. F. (2019). Adapted dance improves motor abilities and participation in children with down syndrome: a pilot study. Pediatric Physical Therapy, 31(1), 76-82.

Merleau-Ponty, M. (2018). Fenomenologia da Percepção. (5ª ed.). Tradução de Carlos Alberto R. de Moura. Martins Fontes.

Organização Mundial da Saúde (2011). Relatório mundial sobre a deficiência. https://apps.who.int/iris/bitstream/handle/10665/7067 0/WHO_NMH_VIP_11.01_p or.pdf?sequence=9

Pantaleão, B. C. D. F. (2019). A contribuição da educação ambiental para desenvolvimento e inclusão da pessoa com deficiência intelectual através do projeto de intervenção: VemSer. (Dissertação de Mestrado). Faculdade de Tecnologia, Universidade Estadual de Campinas, Limeira, SP, Brasil.

Pilates, J. (2011). A Obra Completa de Joseph Pilates: Sua Saúde e Retorno a Vida Através da Contrologia. Phorte Editora LTDA.

Reis, A. D. A. (2016). Educação ambiental e educação inclusiva: possíveis conexões. (Dissertação de Mestrado). Universidade Federal de Sergipe, São Cristóvão, SE, Brasil.

Resende, A. P. C. D., \& Vital, F. M. D. P. (2008). A convenção sobre os direitos das pessoas com deficiência comentada. Recuperado em 05 de junho de 2021 de https://www.gov.br/governodigital/pt-br/acessibilidade-digital/convencao-direitos-pessoas-deficiencia-comentada.pdf/view

Sacks, O. (2006). The power of music. Brain, 129 (10), 2528-32.

Scarpato, M. T. (2001). Dança educativa: um fato em escolas de São Paulo. Centro de Estudos Educação e Sociedade.

Schroeder, K., Ratcliffe, S. J., Perez, A., Earley, D., Bowman, C., \& Lipman, T. H. (2017). Dance for health: an intergenerational program to increase access to physical activity. Journal of pediatric nursing, 37, 29-34.

Souza-Santos, C., dos Santos, J. F., Azevedo-Santos, I., \& Teixeira-Machado, L. (2018). Dance and equine-assisted therapy in autism spectrum disorder: Crossover randomized clinical trial. Clinical Neuropsychiatry: Journal of Treatment Evaluation, 15(5), 284-290.

Teixeira-Machado, L. (2015). Dançaterapia no autismo: um estudo de caso. Fisioterapia e pesquisa, 22(2), 205-211.

Teixeira-Machado, L., \& DeSantana, J. M. (2019). Effect of dance on lower-limb range of motion in young people with cerebral palsy: a blinded randomized controlled clinical trial. Adolescent health, medicine and therapeutics, 10, 21.

Teixeira-Machado, L., Araújo, F. M., Cunha, F. A., Menezes, M., Menezes, T., \& DeSantana, J. M. (2015). Feldenkrais method-based exercise improves quality of life in individuals with Parkinson's disease: a controlled, randomized clinical trial. Alternative therapies in health and medicine, $21(1), 8$.

Teixeira-Machado, L., Arida, R. M., \& de Jesus Mari, J. (2019). Dance for neuroplasticity: A descriptive systematic review. Neuroscience \& Biobehavioral Reviews, 96, 232-240.

Teixeira-Machado, L., Azevedo-Santos, I., \& DeSantana, J. M. (2017). Dance improves functionality and psychosocial adjustment in cerebral palsy: a randomized controlled clinical trial. American Journal of Physical Medicine \& Rehabilitation, 96(6), 424-429.

Trehub, S. E., \& Cirelli, L. K. (2018). Precursors to the performing arts in infancy and early childhood. Progress in Brain Research, 237, 225-242.

Zentner, M., \& Eerola, T. (2010). Rhythmic engagement with music in infancy. Proceedings of the National Academy of Sciences, 107(13), 5768-5773. 